\title{
Reviewing the Aftermath Project (2013-2014) in the Light of Affect Theory
}

\section{Anne Goarzin}

\section{Q OpenEdition \\ 1 Journals}

\section{Electronic version}

URL: http://journals.openedition.org/etudesirlandaises/4828

DOI: 10.4000/etudesirlandaises.4828

ISSN: 2259-8863

\section{Publisher}

Presses universitaires de Rennes

\section{Printed version}

Date of publication: 15 June 2016

Number of pages: 97-111

ISBN: 978-2-7535-5091-9

ISSN: 0183-973X

\section{Electronic reference}

Anne Goarzin, «Reviewing the Aftermath Project (2013-2014) in the Light of Affect Theory », Études irlandaises [Online], 41-1 | 2016, Online since 10 June 2018, connection on 19 April 2019. URL : http:// journals.openedition.org/etudesirlandaises/4828; DOI : 10.4000/etudesirlandaises.4828 


\title{
Reviewing the Aftermath Project (2013-2014) in the Light of Affect Theory
}

\author{
Anne GoarzIN
}

Université Rennes-2 UBL

\section{Résumé}

The Aftermath Project (2013-14) aims at offering insights into comparable experiences of displacement and trauma in times of conflict through an assemblage of online media as well as exhibits throughout Ireland. This contribution suggests that the project goes beyond asserting the sole prism of the Irish Troubles by considering other, more recent experiences of migration to Ireland. As a complex object that is more than what it looks like, I argue that it addresses the interaction between the auto-ethnographic subject, the camera's eye and the critic's, and the role of the network in the circulation and perception of other people's affects and of one's own. To do so, I propose to implement Lisa Blackman's methodology in order to "construct a material-semiotic-affective apparatus that reorients the perception towards new ways of seeing hearing, listening, and feeling".

Keywords: Aftermath.ie, Troubles, migration, intermediality, affect theory, experience, network

\section{Abstract}

Aftermath.ie (2013-14) est un projet qui met en parallèle des expériences comparables de migration contraintes et de traumatismes : y sont assemblés des médias accessibles en ligne et des ouvres qui ont été exposées dans plusieurs lieux en Irlande. Cet article montre comment le projet dépasse le simple prisme des Troubles afin de relayer des expériences plus récentes de migration en Irlande. C'est un objet complexe, qui participe de l'entreprise auto-ethnographique mais interroge aussi la représentation du sujet parlant, son interaction avec l'œeil de la camera ou celui du critique, ainsi que le rôle du réseau dans la circulation des affects des sujets présentés et de celui qui en est le récepteur. Je propose de mettre ici en cuvre la méthodologie "des affects "énoncée par Lisa Blackman afin d'élaborer un appareil critique qui prenne en compte la matérialité physique du projet, la sémiotique et la dimension affective de sa transmission et de sa réception.

Mots clés : Aftermath.ie, Troubles, intermédialité, théorie des affects, expérience, réseau

The Aftermath project was launched in 2013 by director and former Republican prisoner Laurence McKeown. McKeown took part in the Blanket and Dirty Protests in the late 1980s and he was on hunger strike for 67 days. He 
subsequently co-wrote the movie $H 3$, which was released in $2001^{1}$. With the Aftermath project, he took another step as a creative artist and a partner in several creative projects, especially through the Corners of Europe online platform $^{2}$, which offers artistic insights into conflict zones in Europe. Aftermath may be summed up as an intermedial endeavour that aims at "uncov[ering] the experiences and emotions of those who lived through flight and trauma ${ }^{3}$." It resorts to several art forms and uses several media formats in order to discuss and exchange through "creative, artistic approaches to story-telling and life stories to highlight the issues and needs of the participants drawn from the target groups ${ }^{4 \prime}$.

The project was supported by a two-year funding scheme through the EU Programme for Peace and Reconciliation coordinated by Will Glendinning5. Aftermath thus merges two initiatives: one which focuses on recording the narratives of victims and survivors who were displaced from Northern Ireland to the border county of Louth during the Irish Troubles; and another, part of the "Diversity Challenges/Displaced People Programme", which centers on former or recent migrants to Ireland ${ }^{6}$. The connection between both projects is based on the realization that the individuals who migrated to Ireland in the mid-1990s often expe-

1. Written by Brian Campbell and Lawrence McKeown, directed by Les Blair (2001).

2. "CORNERS is a platform for artists and audiences, designed and driven by cultural organisations at the edges of Europe. A number of cultural institutions from the edges of Europe build a partnership designed to last, and based on shared responsibility. CORNERS was initiated in 2010 by six cultural institutions: Intercult (Stockholm), Exodos (Ljubljana), POGON (Zagreb), Drugo more (Rijeka), City Culture Institute (Gdansk), and Umeå 2014 - European Capital of Culture. The project is then further developed together with several institutions, new core partners and associates: Donostia/San Sebastian 2016 - European Capital of Culture, Arts Council of Northern Ireland (Belfast), ISIS Arts (Newcastle), REX (Belgrade), DokuFest (Prizren) and Teatro Pubblico Pugliese (Bari). The list of other collaborating organizations throughout Europe is long, changing and intensely local." [http://www.cornersofeurope.org/about/].

3. [http:/laftermath-ireland.com/].

4. [http:/laftermath-ireland.com/].

5. "Will Glendinning is a former CEO of the Community Relations Council and someone with considerable experience in community relations and community development. Will has worked extensively storytelling as a means of dealing with past conflict. He is trained in the ethical use of storytelling as a healing and reconciling process. Will has participated in European conferences and seminars on conflict. He is a member of Healing Through Remembering, and Bridging Ages. He is assisted by Associate Consultants who are selected on the basis of their skills for particular tasks." [http://www.diversity-challenges.com/about/].

6. "County Louth was very much impacted by the conflict in and about Northern Ireland. Bomb and gun attacks left many dead or injured; others were imprisoned, both North and South. Louth also became a refuge for many who fled the conflict. In more recent times the county has received refugees from further afield, those displaced by conflicts in their own lands. They often experience the same fears, anxieties, hopes, and dreams as their counterparts from the north did; similarly, they also often encounter the same suspicions and prejudices from the host community. Both the victims of conflict and those displaced are now dealing with the legacy of conflict and its impact upon them personally. Diversity Challenges in partnership with, The Integration Centre, the County Museum Dundalk, and the Rural Community Network has received funding from Co Louth Peace and Reconciliation Partnership for support under the EU Programme for Peace and Reconciliation 2007-2013 to deliver two programmes in conjunction with one another." 


\section{after math}

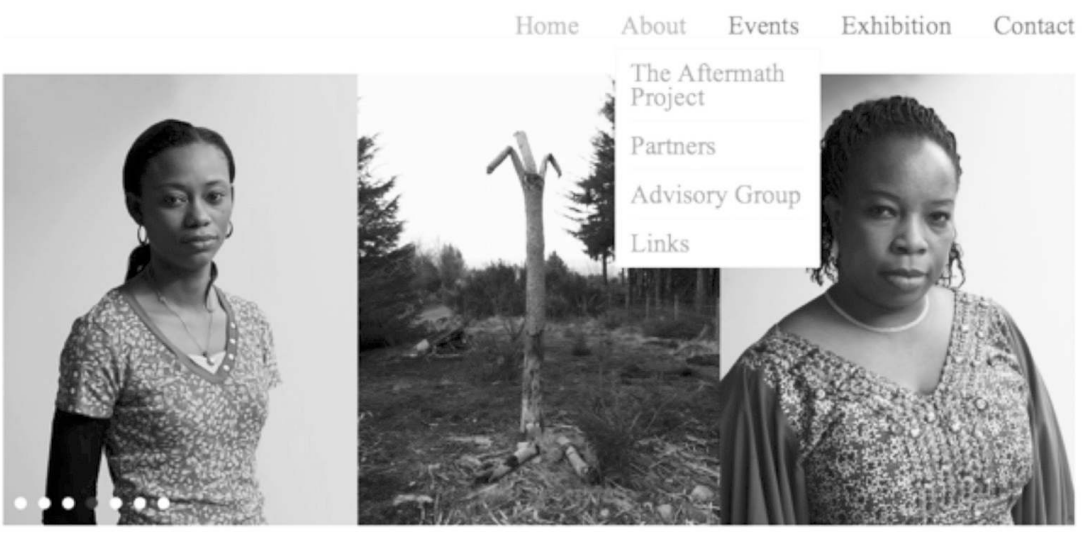

After peace agreements have been signed and the military/paramilitary apparatus of hostilities removed often little visible remains in societies as evidence of the conflict that recently took place. But for many who lived through that experience, or had to flee from it, the scars they carry are all too real and ever-present. Regardless of what side they took in the conflict, or none, they now must make sense out of what happened and where they go from here.

The AFTERMATH Project uses discussion and creative, artistic approaches to story-telling and life stories to highlight the issues and needs of the participants drawn from the target groups. The AFTERMATH Project is

Figure 1: Screenshot of the Aftermath project (http:Ilaftermath-ireland.com/). Tinu Achioya and Tosin Omiyale. Photographs by Anthony Haughey.

rienced the same fears and anxieties as their counterparts who moved south of the border into Co. Louth a generation earlier:

In 1969 the largest evacuation of refugees since World War II took place in Ireland as thousands of people fled across the border to escape the unfolding conflict in Northern Ireland. In subsequent years the border counties continued to be heavily impacted; many people were injured or killed in bombings and shootings whilst others were imprisoned or displaced ${ }^{7}$.

Aftermath was launched at the Louth County Museum, Dundalk, in September 2013 and went on to be shown in Dublin (Temple Bar Gallery of Photography), in Newry (Sean Hollywood Arts Centre), and in Belfast (Belfast Exposed Gallery of Photography) ${ }^{8}$. The output of the project goes beyond the various exhi-

7. [http://aftermath-ireland.com/aftermath-newry-opening/].

8. County Museum, Dundalk, Sept 2013 ; Gallery of Photography, Dublin, 30 Oct-10 Nov; Sean Hollywood Arts Centre, Newry 14 Nov-30 Nov: Belfast Exposed 5 Dec-21 Dec 2013. 
bitions and carries on a life of its own via its website. I argue that the project hinges on two propositions. First, it offers a new perspective on a much-commented political situation by taking into account changing perceptions of the political, the economic and the cultural in the Irish context. It thus goes against the grain of geopolitics in that it does not propose the habitual analysis of the relations of power in the conflict. Rather, it focuses on "capturing the changing cofunctioning of the political, the economic, and the cultural, rendering it affectively as change in the deployment of affective capacity" and chooses to treat the specific question of conflict in Northern Ireland by recontextualising it against the backdrop of displaced populations on a global level. Aftermath is therefore far from being a mere account of the displacement of populations from the North of Ireland to the South : instead, the new space it creates entails a redefinition of the relationship between individuals across communities ${ }^{10}$. Second, the project addresses the effects of a given political situation through the complexity of affects, as expressed by individuals whose stories are recorded, and as experienced by the viewer. As such, it also offers an opportunity to reconsider the method used to address both the political situations and their individual consequences. Indeed, Aftermath exceeds conventional modes of perception in many ways. It does so by tracing previously unrecorded stories : in showing and naming the speakers, it breaks away from the traditional rule of anonymity as well as from the implicit rule of silence enforced within the communities for political reasons ("Whatever you say, say nothing"). Furthermore, one should point out that the virtual dialogue initiated in this way has also led to the emergence of actual discussion groups who have shared their experiences of the Troubles through the physical medium of voice and presence. The project undeniably offers an extended reflection on individual trauma, but the correlation between trauma theory and affect theory requires further clarification in order to understand why the latter might make for a more relevant critical prism here. Patricia T. Clough has referred to trauma as

a forgetting without memory, so that traumatic effects are a symptomology substituting for what was never experienced as such. It cannot be said that there is repression of what is experienced... There is no repression and therefore no possibility of projection or displacement onto the

9. Patricia T. Clough, Jean Halley (eds.), The Affective Turn: Theorizing the Social, Durham and London, Duke University Press, 2007, p. 3.

10. The approach takes into account other traumatic situations, other countries, other experiences of immigration and of migration. This is doubly the case as far as place is concerned : first because the participants have had to move south of the border for safety (from Belfast to Dundalk, or in the surrounding area) : "In an idea originating along the border counties of Northern Ireland, a region which bore the overflow of those fleeing violence in the North, the exhibition takes on a multimedia format in uncovering the experiences and emotions of those who lived through flight and trauma." [http://aftermath-ireland.com/journalist-art-aftermath-exhibition/]. 
other. Instead, trauma is drawn back into the ego. The ego is overrun by the object or event, fixating the ego ${ }^{11}$.

While she acknowledges the importance of Ruth Leys' work (as well as indirectly, that of Cathy Caruth and Dominick LaCapra's landmark essays on trauma ${ }^{12}$ ), in The Affective Turn Clough proposes to take an extra step in interrogating how trauma is passed on "in a transgenerational body trance", or "a haunted materiality ${ }^{13}$ ". She thus wishes to rethink "the subject of trauma as something more like an assemblage of body memories and pre-individual affective capacities ${ }^{14}$ ".

The men, women and children speaking in the Aftermath videos reflect on individual experiences of conflict, violence or displacement which may differ in nature and do not engender identical degrees of repression, hauntings or recurring symptoms. Interestingly, it is Anthony Haughey's photographic triptychs which most evidently point to what may not be stated in the stories : these are individuals who are "ghosted" by the place they originate from, whether it be Ireland, symbolized by boulders, rocks or peacelines, or more remote lands symbolized by the desolation of burnt-out forests or sterile land. (see Figure 1, and Figures 2 and 3). I will therefore argue that the project goes beyond the telling or recollecting of traumatic individual experiences. Rather, it forms what Lisa Blackman has defined an "embodied hauntology... in the profound sense that there is something more to say, one should look for something more than now ${ }^{15}$ ". It thus prompts the researcher to expand the scope of her analysis by taking into consideration "a distributed or mediated form of perception, which is simultaneously somatic, psychic, technical, and historical, and which can animate, stage and, importantly, allow one to 'see' what might actually exceed conventional modes of perception ${ }^{16 "}$. Following Blackman's lead, I will consider the bodily implications of these perceptions for the traumatized ego as well as for the viewer and critic engaging with these bodies through intermediality.

\section{Methodology: Acknowledging Mundane Catastrophes}

Method is thus essential here and it appears to us that recent so-called "affective" methodologies - an offspring of cultural studies - offer a relevant approach

11. Patricia T. Clough quoting Ruth Leys, Trauma: a genealogy, Chicago of University Press, 2000, p. 6.

12. See ibid:; Cathy Caruth, Unclaimed Experience: Trauma, Narrative and History, Baltimore, Johns Hopkins University Press, 1996; Dominick LaCapra, History and Memory after Auschwitz, Ithaca, Cornell UP, 1998.

13. Patricia T. Clough, Jean Halley (eds.), The Affective Turn: Theorizing the Social, op. cit., p. 7.

14. Ibid.

15. Lisa Blackman, "Researching Affect and Embodied Hauntologies: Exploring and Analytics of Experimentation", in Britta Timm Knudsen and Carsten Stage, Affective Methodologies: Developing Cultural Research Strategies for the Study of Affect, NY, New York, Palgrave Macmillan, 2015, p. 26-27.

16. Ibid., p. 26. 
in proposing to address what might be considered as the "blind spots" of trauma theory, notably by taking into consideration what Gregory Forter has called the

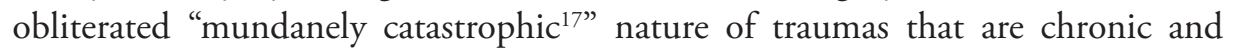
cumulative. Aftermath records individual stories in which traumatic events are woven into the fabric of ordinary lives rather than registered as massive-scale "shock". Let us take one example : in her interview, Karren (born in 1969) highlights the banality of violence for her Protestant family who moved to Newry. She tells of the family's alarm on hearing a shooting at a neighbour's house, or recalls sleeping undisturbed through the banging of bin lids during Internment protests, much to her relatives' astonishment. She also remembers her frustration about the aborted friendship with a fellow girl Scout, because she was a Catholic. The way she recalls what was for her a happy childhood only accentuates the physical assimilation of constant threat: "Maybe looking back now it wasn't that normal, you know, mortar bombs, and hiding in the hall afraid and saving the $\operatorname{dog} . .$. but it was all I knew ${ }^{18} \ldots "$

Moving from the "felt sense articulated as an emotional stance or attitude ${ }^{19 "}$, the researcher's aim in "cultivating methodological sensitivities" is to allow a movement "through [felt sense] into a particular archive of connected statements, practices, objects, subjects that give form and transform one's embodied responses ${ }^{20}$ ". The Aftermath project offers an opportunity to implement a new methodology which may be loosely defined as an experiment with a variety of related media including photography, visual sculpture, storytelling and music, which proximity induces "affect transformation". How to interpret this variety of experiences and what is at work when engaging with "immaterial and affective processes of social life ${ }^{21}$ " is what recent academic criticism has been attempting to circumscribe. "Developing affective methodologies is, of course, a huge challenge", Knudsen and Stage admit : "How do you identify affective processes and discuss their social consequences through qualitative research strategies if affect is bodily, fleeting and immaterial and always in between entities or nods ${ }^{22}$ ?" Cultural theorist Lisa Blackman has the following response :

17. Like persecution or genocide: "I am speaking here of the trauma induced by patriarchal identity formation rather, say, that the trauma of rape, the violence not of lynching but of everyday racism.”, p. 260 in Greg Forter, "Freud, Faulkner, Caruth: Trauma and the politics of the Literary Form", Narrative 5: 3, October 2007 , p. 259-85. Quoted by Anne Goarzin, "Articulating Trauma ", Études Irlandaises, Perspectives on Trauma in Irish History, Literature and Culture, 36/1, Rennes, PUR, 2011, p. 18.

18. "Karren interview" [https://soundcloud.com/joe-obloggs] retrieved 18 March 2016.

19. Lisa Blackman, "Researching Affect and Embodied Hauntologies: Exploring and Analytics of Experimentation”, art. cit., p. 28.

20. Ibid.

21. Britta Timm Knudsen and Carsten Stage, Affective Methodologies: Developing Cultural Research Strategies for the Study of Affect, New York, Palgrave Macmillan, 2015, p. 1.

22. Ibid., p. 2. 
Method does not reveal or disclose a pre-existent object or even a process, but rather the analytics of experimentation that I develop attempts to construct a material-semiotic-affective apparatus that reorients the perception towards new ways of seeing hearing, listening, and feeling. The methodological apparatus helps to "give form" to processes that are dispersed, distributed across space and time ${ }^{23} \ldots$

In other words, the visual, verbal and auditory dimension of the project show how bodies are modulated by affect (how they react or express themselves) while the critic aims at deploying her "material-semiotic-affective apparatus" to engage with them.

From the perspective of those telling their stories, asserting one's presence appears to be empowering. Telling of their experience and questioning power structures or social rules enables the speakers to reassess how communities, whether they are older Irish exiles or more recent migrants envisage their experiences and their future. For instance, two Serbian girls ${ }^{24}$ speak of how they have been in "direct provision for nine years", living in hostels and struggling to adapt to new schools as they move from one accommodation to the next ("very confusing and very hard"). One of them hopes to become a lawyer to help other asylum seekers with communal law, the other wants to be an actress in order to become wealthy enough to "come back and help children" such as themselves. Both value the sense of community provided by their being part of a youth club that takes them places in Dublin and both are able to enunciate a future which is conditioned by their ongoing, present experience of displacement.

Aftermath thus embodies personal experiences of trauma, displacement and political violence by resorting to the digital medium, as well as redirecting them through the flux and flow of the network. It also facilitates a dialogue between the "mundane" yet traumatizing experience of a displaced Northern Irish community which escaped to the border counties to flee the violence of the conflict in the late 1960s and that of non-White, non-Western migrant subjects who have come from Serbia, Pakistan or Africa ${ }^{25}$. What is restored in the process is what some critics claim has been omitted in trauma theory, namely the ability to listen to the other $^{26}$. Here, the intensity of the subjects' experiences is shared through the dedicated website and it is circulated through alternative, and participative networks

23. Lisa Blackman, "Researching Affect and Embodied Hauntologies: Exploring and Analytics of Experimentation”, art. cit., p. 26.

24. "Serbian girls audio" [https://soundcloud.com/joe-ebloggs] retrieved 18 March 2016.

25. See “Toisin interview” [https://soundcloud.com/joe-ebloggs] retrieved 18 March 2016.

26. See for example Stef Craps and Gert Buelens, "Introduction: Postcolonial Trauma Novels", Studies in the Novel, vol 40, $\mathrm{n}^{\circ} 1$ \& 2, Spring and Summer 2008, p. 1-12; or Victoria Burrows, "The Heterotopic Spaces of Postcolonial Trauma in Michael Ondaatje's Anil's Ghost, Studies in the Novel, vol. 40, $\mathrm{n}^{\text {os }} 1 \& 2$, Spring and Summer 2008, p. 161-77. 
such as YouTube or Soundcloud. The musical pieces created ${ }^{27}$ or the sound sculpture $^{28}$ both support the force of the narratives and divert it towards other, possibly more universal forms. The artistic and cultural assemblages of Aftermath enable us to theorize affect, in Patricia Clough's words,

in relation to the technologies that are allowing us both to "see" affect and to produce affective bodily capacities beyond the body's organic-physiological constraints. The technoscientific experimentation with affect not only traverses the opposition of the organic and the non-organic; it also inserts the technical into felt vitality...the affective turn, therefore, expresses a new configuration of bodies, technology, and matter instigating a shift in thought in critical theory ${ }^{29}$.

In so doing, the Aftermath project challenges conventional interpretations : it moves beyond simply relaying "the equilibrium-seeking closed systems" developed by individuals to cope with trauma, and towards "the complexity of open systems under far-from-equilibrium conditions of metastability ${ }^{30}$ " which value circulation. The first looks back to the past, while the other "sends thought to the future - to the bodily matter and biotechnologies of technoscientific experimentation ${ }^{31}$ ".

It invites a method which P. T. Clough describes as "a transdiciplinary approach to theory and method that necessarily invites experimentation ${ }^{32}$ ". I would agree with theorists such as Brian Massumi, Gregory J. Seigworth and Patricia T. Clough that while war and cultural transformations are crucial as such, the turn to affect registers a change in the co-functioning of the political, the economic, and the cultural, or what Massumi elsewhere dubs "the social ${ }^{33}$ ". Aftermath may thus not be envisioned as a strictly Irish story, as one would almost expect it to be due to long-standing methodological assumptions - that storytelling is an Irish phenomenon; or that displacement may only be read through the prism of the Irish diaspora. Rather, it points to the possibility of considering the impact of world conflicts and cultural and economic imperialisms, as well as common human, affective responses to contemporary changes, from the Troubles to the recent, if painful awareness of Ireland's place in a global environment during the economic boom, and after the collapse of the Celtic Tiger economy.

Instead of offering one single interpretation, Aftermath seems to shoot off in various directions and to provide multiple temporalities : that of the subject repre-

27. "Song for Michael" by David Holmes/Keefus Cianca, and "Aftermath" piece by Elaine Agnew.

28. An audio installation by Anthony Haughey, produced by Recordit studios, 2013.

29. Patricia T. Clough, Jean Halley (eds.), The Affective Turn: Theorizing the Social, op. cit., p. 2.

30. Ibid.

31. Ibid.

32. Ibid.

33. Ibid., p. 3. 
sented, that of the group or of the community of viewers, and that of the researcher. Depending on which featured medium the viewer chooses to focus on, and whether it is one that affects the viewer's body more directly, or one that relies on language to express affects, Aftermath elicits both approaches, either connecting emotions with bodily sensations or with cognitive reception. According to Knudsen and Stage, this determines a split between what first "hits us" on the one hand, and, on the other, intellect or cognitive apparatus where affect is considered "beyond language categorization, and therefore, any analytical strategy must focus on semantics and semiotics as distorted traces of affect, not a medium for $\mathrm{it}^{34}$ ". This involves reflecting on the condition of the social and a conscious experience, and demands that one question the "situational specificity" of the project in order to understand its context and historical entanglements, and to take in the affects and make meaning ${ }^{35}$.

\section{Changing Perceptions : Questioning Spaces and Temporalities}

Aftermath incorporates individuals as bodies in a virtual space which is no longer limited to the politically contested and geographically elusive borders of nation, but as an assemblage of artistic works and witnesses' accounts (be it victims of the Troubles or victims of other, sometimes more global conflicts) that reaches beyond what may be seen as its "starting point", or as its situational context. It also places itself against the determinism of material conditions and the normativizing discourse on the Troubles by exceeding the boundaries of the norm exemplified in binary social or historical discourses - North, South, victim, perpetrator, Republican, Loyalist. On the contrary the project refutes spatial utopias and the definition of a national space by allowing the subject to come into being as itself (as an Albanian emigrant child from Serbia, as a Nigerian woman, as the son of a Catholic displaced family from Stranmillis in Belfast whose father was killed in a pub bombing in 1975).

As far as the Troubles are concerned, Aftermath opts for a different approach to these predetermined socio-spatial conditions, notably by addressing issues of

34. Britta Timm Knudsen and Carsten Stage, Affective Methodologies, op. cit., p. 4. For example, "The affective turn" is also one which, as Seigworth and Gregg state, attempts to "turn away from the much-heralded "linguistic turn" of the latter half of the $20^{\text {th }}$ century, - from cultural anthropology to geography to communication and cultural studies to performance-based art practices to literary theory..." (The Affect Theory Reader, 2010, p. 14). To them, the turn to the affect consists of "understanding how the 'outside' realms of the pre/ extra-/para-linguistic intersect with the 'lower' or proximal senses (such as touch, taste, smell, rhythm, and motion-sense or, alternately/ ultimately, the autonomic nervous system) while also arguing for a much wider definition for the social or the cultural." (ibid., p. 7-8).

35. See Britta Timm Knudsen and Carsten Stage : "This interest in 'the situational' is... directed by our wish to not only get close enough to the actual affectivity of social life to sense and detect it, but also by our interest in knowledge production that transcends solely subjective accounts of affect." (p. 5). 
police collusion with paramilitary groups in the case of the Brecknell murder ${ }^{36}$, and by pointing to the tragic irony of being brutally killed after having assumed his family would be safe in Dundalk. As such, the project also queries what sociologist Allen Feldman dubs the "imagined community of utopian completion" that is based on a continuum: "In Northern Ireland the formation of the political subject takes place within a continuum of spaces consisting of the body, the confessional community, the state, and the imagined community of utopian completion: United Ireland or the British Ulster ${ }^{37}$."

Being located in the virtual space of the Internet allows Aftermath to challenge these definitions and to liberate itself from what Peggy Phelan has exposed as "critical theories of cultural reproduction [...] increasingly dedicated to consideration of the 'material conditions' that influence, if not completely determine, social, racial, sexual and psychic identities ${ }^{38}$ ". Here, the people telling their stories are allowed to disentangle themselves from the geopolitical space and to define their own individual perception of space (the farm, the field, the home, the street). They become inscribed in a new time and space through the format of the storytelling sequence (about 10 minutes in length), which makes for a mental exploration of the places of the past recalled in the present and not erased. Strikingly, while many of these Irish stories recall traumatizing events (the kidnapping and killing of a mother, the disappearance of an uncle, the explosion and deaths in a pub, etc.), the hyperbolic eruption of political violence is put in perspective with the continuity of daily life, affective connections within the communities and outside of them. The new space that is being created is that of "life itself3". The Aftermath project therefore chooses to risk human encounters and to reconfigure the relationship with the other (sometimes the former adversary), as much as with the other as viewer / Internet user, who is also collecting and reflecting on these individual stories.

36. “On December 19, 1975 a car bomb exploded outside Kay's Tavern in Dundalk, Co Louth. Two people died and dozens were injured. On the same evening gunmen opened fire both outside and then inside Donnelly's Bar, Silverbridge Co Armagh. A bomb was thrown into the bar. Three people died and again dozens were injured." "Alan (Brecknell) interview". Brecknell went on to work at the Pat Finucane center, [http://www.patfinucanecentre.org/collusion/opb_fami.html]. The Center's activities comprise; "Justice for the Forgotten - JFF, a project of the PFC, provides support and advocacy to victims and survivors in the Republic including those bereaved and injured in the Dublin and Monaghan bombings; Networking with human rights NGOs and parliamentarians in Ireland and abroad; Long-term involvement on a wide range of issues surrounding policing and the criminal justice system; Facilitating dialogue between the two communities in the North through private contacts, workshops and public meetings on potential truth processes etc.; Individual casework with families who have lost loved ones and creating support structures for families."

37. Allen Feldman, Formations of Violence: The Narrative of the Body and Political Terror in Northern Ireland (revised second printing, 1994, third printing, 1997) Chicago, The University of Chicago Press, p. 9.

38. Peggy Phelan, Unmarked: The Politics of Performance, London, Routledge, 1996, p. 5.

39. Patricia T. Clough, Jean Halley (eds.), The Affective Turn: Theorizing the Social, , op. cit., p. 3. 


\section{Choices : The Editorial Process}

How this "affect transformation" occurs makes for the second aspect of our analysis. Much like photographic artist Anthony Haughey's commissioned portraits $^{40}$ evince a deliberate choice of the subject, framing and setting (see figure 2), the project edits and selects its texts and productions.
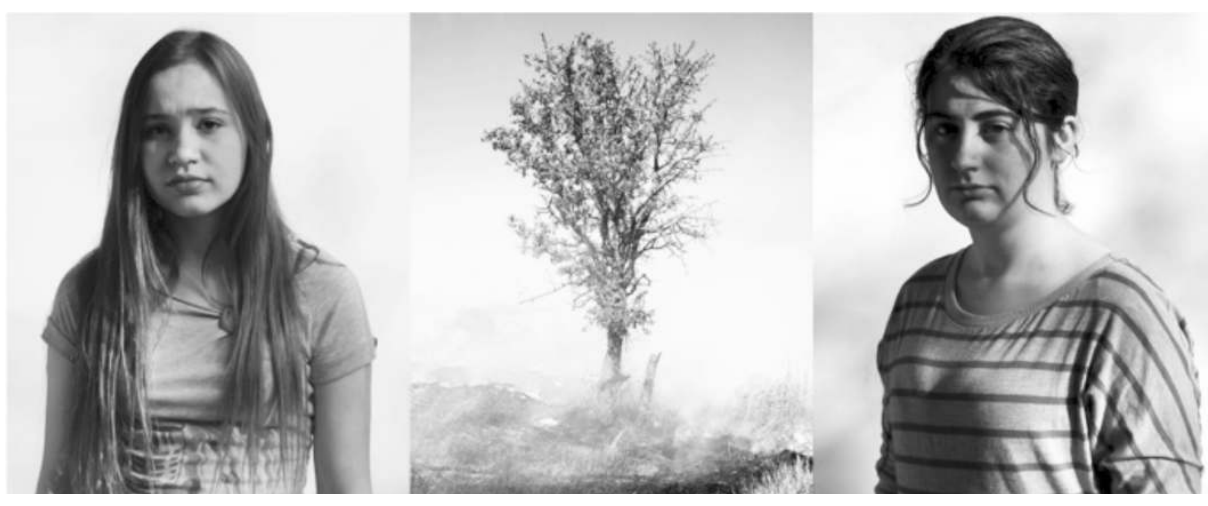

Figure 2: Aftermath Project. Emanuela and Englentina Doda. Photographs by Anthony Haughey ${ }^{41}$

The strength of Aftermath lies in its ability to convey affects which are offered the unlimited virtual space of the web, and of virtually unlimited audience. Not only does it open up the scope of the conflict as global and no longer in terms of strictly Irish geography or politics, but in terms of how other people might experience it in a physical way, through affects.

The 10-minute videos also reveal an ongoing interaction, and sometimes a renewed dialogism between the speaker and the producer Laurence McKeown, whose voice is heard at times and whose face is framed by the camera. Sometimes there is also added archive footage to illustrate the story. What emerges out of this is the possibility of a recreated community between the viewer and the subject, as the reality of the latter's affect-laden experiences (of fear, anxiety, loss) are likely to be shared in a very real, bodily way, through tears, or as one searches for a physical expression of these emotions on the speaker's face. As performance critic Peggy Phelan argues: "Memory. Sight. Love. All require a witness, imagined or real ${ }^{42}$." Sometimes, they reveal the connection between the interviewee and Laurence McKeown, the project director and allow for interlocution (as is the case with RUC interviewee Roger McCallum). A glimpse behind the scenes suggests

40. See also the complete series of portraits online [https://issuu.com/anthonyhaughey/docs/ah_aftermath_issuu/1].

41. [http://aftermath-ireland.com/aftermath-series-by-anthony-haughey/].

42. Patricia T. Clough, Jean Halley (eds.), The Affective Turn: Theorizing the Social, op. cit., p. 3. 
this is no solitary moment or confession, but a rather an on-going conversation with oneself and with the community, post-conflict.

The use of various, complementary media reinforces the dialogical strength of the project: the individual stories are also taken into Haughey's photographs, which has unrelated people feature on the same triptych, and also connects them to a place or to a specific object which determines the discontinued space that the speakers have been confronted with by being moved forcibly to another city or country. As far as the conflict is concerned, the discontinuity and violence of space is symbolized by concrete blocks on the border; by a bullet hole in a window, by walls or peace lines : semiotics make for the lack of a verbal language and stand for what Knudsen and Stage call "distorted traces of affect ${ }^{43}$ ".

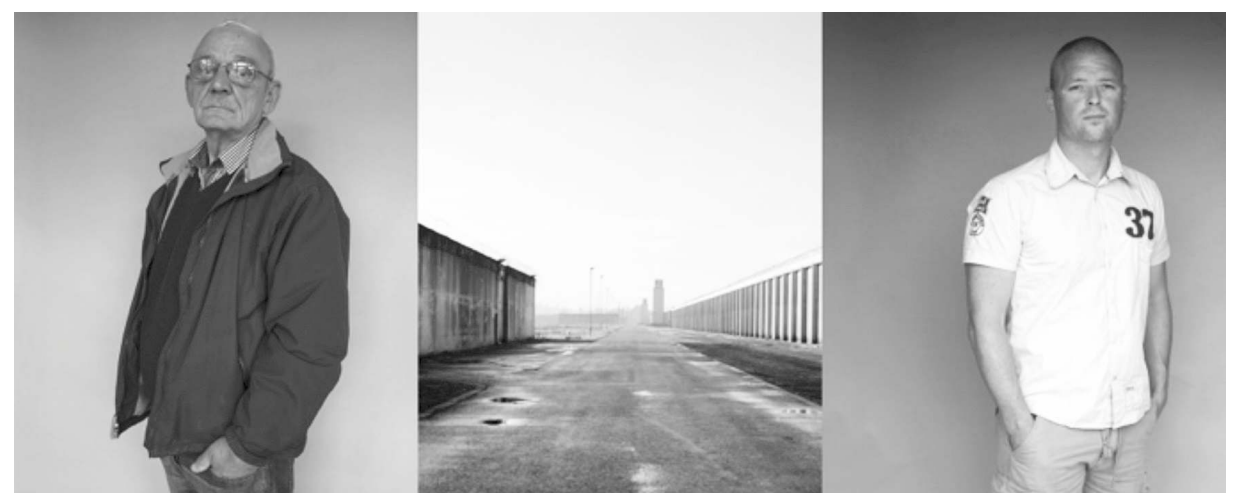

Figure 3: Aftermath Project. Tony Martin and Mark O'Connor. Photographs by Anthony Haughey.

What makes the project particularly stimulating is the proliferation of its practices: it offers access to fixed or moving images, to music, to combined music and image in the sound sculpture, thus stressing the possibility of an ontological order different from that of purely linguistic representation. Browsing through the different media literally triggers "mixed feelings" on the viewer's part, ranging from empathy to anguish and sadness - and most of all, it arouses non-intentional emotions. While the sound sculpture's entangled voices may initially seem to convey a certain confusion, it also posits as acceptable an unstable, uncertain or fleeting understanding of the situation on the part of the non-Irish viewer, or of the researcher. More interestingly, the multiple voices dematerialize expression and disconnect language from the bodies that speak it. The environment created here is an assemblage of disconnected corridors, veiled partitions, light and darkness, haunting violin music associated with murmuring or pleading

43. Britta Timm Knudsen and Carsten Stage, Affective Methodologies, op. cit., p. 4. 


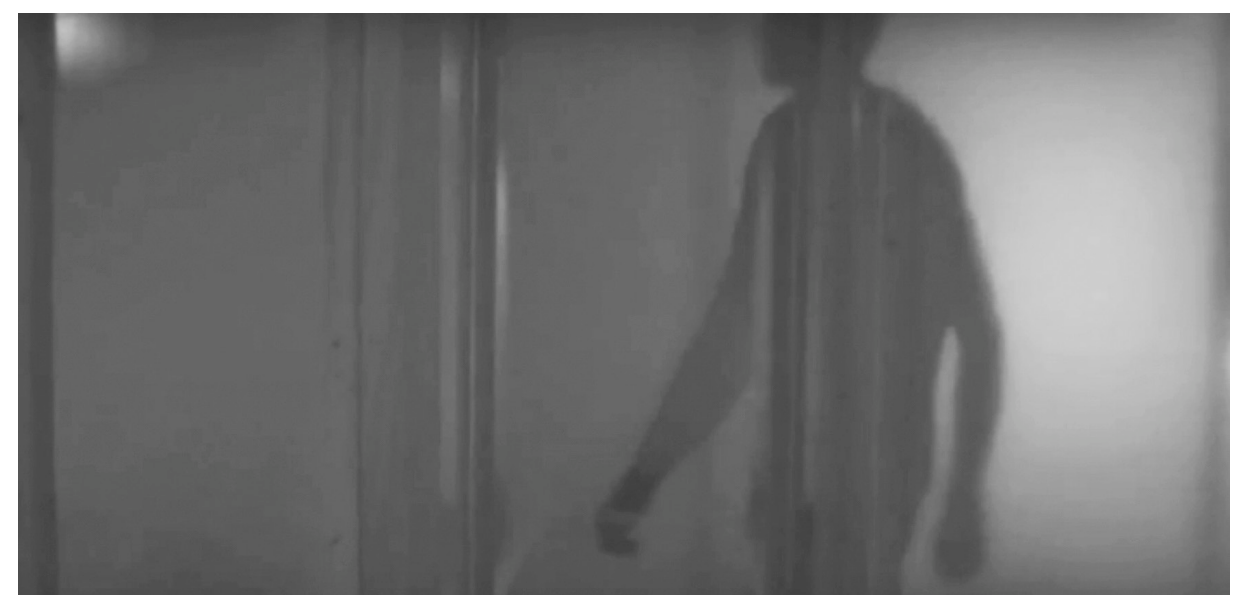

Figure 4: "Aftermath": Sound sculpture (screen shot). Photographic artist Anthony Haughey, music composer Elaine Agnew.

voices - male, female, foreign-sounding or Irish voices -, and claiming "This is my story... I want to tell you my story".

More so than the homeostatic form of the interviews, this "sound sculpture", proposes to assemble two seemingly incompatible techniques (auditory and material), thus generating a new hybrid "embodied" object. It also suggests the possibility that the subject might be co-constructed with the environment and it defines a new relationship between bodies (as voices) outside the limits of individual often traumatic bodily experience. In other words, it points to the fact that from this "cell-like" system (or nucleus, in the scientific sense), a new form arises which challenges linearity. For P. Clough, this is a crucial intellectual turn, because "this move away from privileging homeostasis to thinking evolution in terms of information, complexity and open systems under far-from-equilibrium conditions of metastability undoes the opposition between the organism and the environment, as well as the opposition between the organic and the nonorganic ${ }^{44}$ ". The fact that various networks (such as SoundCloud recently, YouTube or Twitter to a lesser extent) also give access to the sound sculpture and the interviews is similarly interesting, because they further circulate the media, thereby disentangling it from the context of the 2013-14 project. Far from a compulsive repetition of trauma, what is taking shape here is a new non-organic object. The Aftermath project thus veers to the future and fosters a life drive rather than a death drive by creating a lively, self-organized network that reconfigures "bodies, technology, and matter ${ }^{45}$ ".

44. Patricia T. Clough, Jean Halley (eds.), The Affective Turn: Theorizing the Social, op. cit., p. 12. 45. Ibid. 


\section{Conclusion}

Listening to the interviews, some recurring terms stand out, such as "normality, "abnormality", "disclosure", or "knowledge" and "truth". Issues of belief and trust are at stake here. Something happens, whereby a new definition of the speaker's identity as feeling subject rather than as authorial presence is provided, as well as a renewed definition of the interlocutor, as someone who is affected by the other's bodily presence and thus himself experiencing a form of discontinuity. Here, telling one's story is a way for the "I" to avoid fading and to summon memory and love while displaying it for others to hear or see makes sure the "eye" of the spectator is requested. Unique stories are being told here, the performance of which seeks to establish the truth and to settle the facts (what happened to Dominic McGinley's parents or to Seamus Dollan, who was found dead in a ditch ; or how Emmanuel Marley's father was killed by Loyalists). Aftermath offers a virtual place for these narratives which, A. Feldman might say, have "overburd[ened] experience with surplus meaning ${ }^{46 "}$ ". Traditionally, Phelan argues, "visibility politics are additive rather than transformational... They lead to the stultifying 'me-ism' to which realistic representation is always vulnerable. Unable to see oneself reflected in a corresponding image of the same, the spectator can reject the representation as 'not about me'. Or worse, the spectator can valorize the representation which fails to reflect her likeness, as one with 'universal appeal' or 'transcendent power'47" What is central in Aftermath is no longer identity or difference, the matching image of "me as the same" or the comforting image of "me as different", but the co-construction of a new identity through autonomous artistic creations.

Aftermath succeeds in defining a new identity which no longer comes as an excess but as a transformation through the use of intermedial forms. One can appropriate it, or circulate it in a variety of contexts ${ }^{48}$. In this sense, Aftermath goes beyond the representational logics of dissension between the "self" and "other" understood in terms of politics: instead, it "assembles" experiences by enhancing what is not immediately visible. I have shown that Aftermath assembles practices and is therefore not a singular object, but a networked project. Because it selects the data collected, it does not make a bid for universality and does not claim to provide clear-cut "answers" or fixed perspectives - and as such it may be said to remain partial. There is an autoethnographic dimension to it, because

46. A. Feldman, Formations of Violence: The Narrative of the Body and Political Terror in Northern Ireland, op. cit., p. 15. 47. Peggy Phelan, Unmarked: The Politics of Performance, op. cit., p. 11.

48. See Camilla M. Reestorff, "From Artwork to Net-work: Affective Effects of Political Art", in Britta Timm Knudsen and Carsten Stage, Affective Methodologies, op. cit., p. 203. 
it "engages multiple participants in participatory art practices ${ }^{49}$ ". However as C. Reestorff has pointed out, "the ethnographic turn has been accompanied by another turn, namely an ethical turn in which an art-work is evaluated 'on the degree to which artists supply a good or bad model of collaboration ${ }^{50}$ "... meaning that the efficacy of art is often perceived in terms of its ability to improve human behavior. I suggest that Aftermath cannot be studied merely as an autoethnographic or an ethical object : while it is both these things, it also engages the viewer to address its shifting artistic borders and the dissemination of its online narratives through the networks, prompting a reflection on the circulation of data and on what C. Reestorf has called the "shift from art-work to net-work" ${ }^{51}$ ". "Affective methodologies" thus appear as a relevant tool to analyse the reality of experience and to challenge fixed epistemological frames. They also allow to study creativity and the coming together of phenomena in the ever-expanding network (rather than field, perhaps), of Irish studies.

51. Camilla M. Reestorff, "From Artwork to Net-work : Affective Effects of Political Art”, art. cit., p. 204. 